\title{
Using Technology to Engage Students and Build Learning Communities to Inform Instructional Decisions
}

\author{
By Carol Todd ${ }^{*}$ \\ Victoria Anyikwa ${ }^{\dagger}$ \\ Nancy Ryan \\ Patricia Tobin ${ }^{+}$ \\ Nancy Wood $^{*}$
}

\begin{abstract}
Saint Leo University is a liberal arts university located in southwest Florida. University campus is a residential campus that teaches the traditional aged student. The campus population is 1,800 students who are mostly Florida residents, with international students representing 18 different countries. Twenty-one centers located in seven states support non-traditional student populations that may be civilian or military. The Center for Online Learning (COL) enrolls over 3,000 students who earn bachelor and masters' degrees. The School of Education and Social Services offers undergraduate and graduate programs on campus, in centers and online in criminal justice, education, human services and social work. Throughout the university and the School of Education and Social Services core values are infused in all classes. In this session faculty who teach undergraduate and graduate classes in education, social services and human services will present how they infuse emerging technologies to design and implement instruction. Panel members will discuss effective strategies in technology, utilized across disciplines, to facilitate learning and build successful community, whether the class setting be an online platform, face-to-face or blended class. The panel will share how they quantitatively and qualitatively assess the effectiveness of the diverse technologies to support student learning modalities, critical thinking and application of course content. The panel's discussion will convey the ways in which they promote dynamic student interactions and collaborations with instructors and peers. Speakers will provide a summary of how they use this information to inform instructional decisions within
\end{abstract}

\footnotetext{
*Assistant Professor, Saint Leo University, USA.

${ }^{\dagger}$ Associate Professor, Leo University, USA.

^Associate Professor, Saint Leo University, USA.

${ }^{+}$Associate Professor, Saint Leo University, USA.

A Assistant Professor, Saint Leo University, USA.
} 
their specific disciplines which results in deeper understanding of course content.

\section{Introduction}

Saint Leo University (SLU) is a liberal arts Catholic university located in southwest Florida (USA). The University is unique in that it serves and offers graduate and undergraduate courses to students in many different locations and through a variety of delivery methods. University campus is a residential campus that teaches the traditional aged student. The campus population is approximately 1,800 students who are mostly Florida residents, with international students representing 18 different countries. Twenty-one centers located in seven states support non-traditional student populations that may be civilian or military. The Center for Online Learning (COL) enrolls over 3,000 students who earn bachelor and master's degrees.

The University's Benedictine foundation of Core Values (Respect, Integrity, Personal Development, Community, Responsible Stewardship, and Excellence) holds the university community accountable to students no matter where they are located. Throughout the university core values are infused in all classes and university activities. The University developed and subscribes a model of preferred pedagogy for all courses whether online, blended or face-toface. Our preferred pedagogy challenges traditional pedagogical models of curriculum delivery and is a change in philosophy from "stand and deliver" to active learning techniques. At times, this implementation can be challenging to create a sense of community in the online classroom.

Much of the power of learning in an online classroom relies in its capacity to support multiple modes of communication including any combination of student-student, student-faculty, faculty-student, etc. Taking into account the various learning styles of students and providing opportunities for self-directed and collaborative learning, educators can facilitate formidable and valuable online course experiences geared to achieving identifiable learning goals and outcomes and creating a sense of community using an array of resources and capabilities available to online learning.

Much has been written on the difficulty of creating a sense of community in an online classroom. Research demonstrates a students' sense of community in an online classroom relies on the interactions between his or her classmates and the course instructor and there is a lack of appearance-based factors that could deter self-expression. Due to the somewhat anonymity in an online forum, online students may self-disclose to a larger extent than in sitting in the traditional face-to-face classroom; hence creating a strong sense of community online than in an on ground setting. Online tools and technologies can assist instructors in creating a sense of community to enhance their teaching and student learning in an online classroom. Instructional practices foster student connectedness in online environments. Research has found classroom community and student engagement are closely related to each other (Bikowski, 2007; Vesely, Bloom, \& Sherlock, 2007; Young \& Bruce, 2011). 
This research paper will further study this topic by comparing instructor and student perceptions about building community in online course settings across three disciplines (education, human services and social work).

\section{Review of the Literature}

During the past three decades, educators have discussed the efficacy of utilizing computer technologies to teach in a virtual environment. Early tutorial, programmed learning approaches did little to foster higher levels of critical thinking through interaction. As new technologies emerged, on-line learning experiences have moved beyond the delivery system toward creating viable, dynamic and engaging communities of learners (Schon, 1999; Roth, 1998). These virtual communities predicate the values of community that relate to the social construction of knowledge. The instructor's planning and interactions facilitate interactions which impact both cognitive and affective learning domains. As students interact with one another and with their instructor, they collectively create a shared knowledge. Web-based technologies, asynchronous and synchronous chatrooms, and online conferencing have enabled students and instructors to ask questions, share observations and connect deeply regarding their learning experiences. Instructors can utilize student questions, comments and feedback to strengthen course content in authentic and meaningful ways.

In a virtual classroom, research demonstrates that the online presence of the professor is a key factor for a successful online learning experience (Lehman \& Conceicao, 2011; Smith \& Caruso, 2010; Young, \& Bruce, 2011). Indicators of teaching presence include online classroom activities such as, exchanging of information and feedback related to course content, continuous communication with students, and providing a sense of community (Palloff \& Pratt, 2003). Virtual classroom community has been defined as the shared connection between and among students and professor that result to the achievement of course outcomes (Young \& Bruce, 2011). While virtual classrooms do not have the advantage of physical proximity found in face-toface classrooms, technology does provide numerous and innovative opportunities and alternatives to allow students to experience a virtual classroom community. Some of the widely recognized virtual classroom web tools that professors utilize to interact with students include social media, microblogging, avatars, video sharing, RSS feeds, wikis, and blogs.

Educators define community in numerous ways. Garrison (2007) defined a learning community as "a group of individuals who collaboratively engage in purposeful critical discourse and reflection to construct meaning and confirm mutual understanding" (p.62). Students' sense of community in a virtual learning classroom comes primarily from the interactions with peers and professors (Drouin, 2008; Liu, Magjuka, Bonk \& Lee, 2007; Outzs, 2006). Student perceptions of a sense of community in the virtual classroom correlate 
to the quality of their peer interaction (Drouin, 2008 \& Outzs, 2006). Studies find a correlation between student's sense of community and their satisfaction with course achievement and social interactions (Drouin, 2008; Liu, et. al, 2007; Outzs, 2006). Online pedagogical practices may serve as a critical factor in student satisfaction and sense of community. Online teaching methods and sense of community have a strong correlation with student performance and overall satisfaction (Dennen, Darabi, \& Linda, 2007). Ouzts (2006) discovered that students who reported low sense of community acknowledged little interaction with fellow students and dissatisfaction with both the teacher and course learning. Dennen et al. (2007) emphasized that online teachers may lack a comprehension of quality community-building communication techniques that cultivates a sense of community online.

McMillan and Chavis (1986) defined sense of community as, "a feeling that members have of belonging, a feeling that members matter to one another and to the group, and shared faith that members' needs will be met through their commitment to be together" (p. 9). In the online environment, a sense of community is not immediate. One key factor important to collaboration and interaction has been described as learners having a social presence, which Swan (2002) described as composing two factors, immediacy and intimacy. In an asynchronous environment, where there is no face-to-face contact, the urgency for social presence is even greater in order for students to feel connected to each other and to the instructor.

Garrison, Anderson, and Archer (2000) refer to social presence as the development of the climate and relationships among learners in the online environment. (Chun-Wang, Nian-Shing, \& Kinshuk, (2012) defined social presence of having three components, co-presence, which refers to a subjective experience of togetherness with other learners; intimacy, which refers to a degree of trust and a sense of bonding with other learners; and immediacy, which refers to the learners perceived directness and the interactions with other learners, or how they feel they are treated by others in the online environment.

The Community of Inquiry (CoI) (Garrison, Anderson, \& Archer , 2000) framework has generated considerable interest among online learning researchers and suggests that value driven discussion postings are placed into the following categories; social presence, cognitive presence, or teaching presence. Students play a role in creating a community of learning by projecting their individual characteristics into the virtual classroom. Much has been written about the challenges of creating a sense of community online (Allen \& Seaman, 2011; Lehman \& Conceicao, 2011; Rheingold, 2010). Yet, some research suggests that the virtual online classroom lacks appearancebased factors which often hinders self-expression and sets the stage for stereotypical expectations; possibly due to the anonymity of the asynchronous mode lending itself to more self-disclosure (Garrison, Anderson, \& Archer , 2000; Arbaugh, Bangert, \& Cleveland-Innes, 2010).

For teaching presence, Garrison and colleagues (2000) assert that while interactions between participants are essential in virtual classroom environments, exchanges in and by themselves are not enough to guarantee 
effectual learning. These interactions require distinctly defined parameters and be highly focused toward an exact outcome. Garrison et. al (2000) detail teaching presence as the design, facilitation, and direction of cognitive social processes for the reason of achieving consequential and pedagogically meaningful learning outcomes.

\section{Purpose and Methodology}

This research paper will further study various aspects of community in online and face-to-face environments by comparing instructor and student perceptions of building community in online courses across three disciplines (education, human services and social work). Instructors in these disciplines implemented various strategies and technologies in their classes and assessed the effectiveness of these in building community and increasing student engagement. Methodology will be discussed by discipline.

\section{Education}

Two studies were conducted in education; instructors in reading and exceptional student education surveyed students enrolled in online classes. First, after completing their second online graduate course in SLU's master's of Reading program, students in two cohorts completed a survey comprised of 10 questions related to mastery of course content and student perceptions of the development of community within the online classroom. Students in one cohort (Cohort A) were were invited to join Elluminate at a specified time. Students in a second cohort (Cohort B) were given a choice as to what time the class would hold its Elluminate sessions, with specific purposes stated for their active participation. Survey questions included a 4-point Likert scale, ranking and short answers. Students were sent a link to the anonymous electronic survey link, with a short email inviting them to help the professor strengthen the course by providing feedback. Consent was implied if participants responded. Taxonomic analysis of end of course evaluations also provided data for this pilot study.

Throughout the classes, the instructor initiated behaviors to foster socializing students to an online community of learners. These instructor initiated behaviors included:

1. Setting an expectation that everyone participates in Elluminate sessions by asking what works best and trying to adjust her schedule accordingly

2. Sending emails telling students of the sessions; 5 students came

3. Creating announcements for all students telling of the productivity achieved after each session

4. Following through when students asked to create a list of emails (only from those students who gave written permission) 
5. Responding to emails in a timely manner

6. Modeling various ways of supporting and talking with one another on the chat board

7. Encouraging students to share a great deal during Elluminate sessions and on the chatboard

8. Each week, students express gratitude for the instructor's willingness to hold Elluminate sessions so "they could talk together" and "get answers to their questions" regarding course content and assignments. The instructor thanked students for their participation.

Second, instructors in the Department of Graduate Education conducted a research study investigated an emerging technology (Elluminate - an online conferencing tool) in online environments. The investigation utilized a survey design; an external link to the survey (quantitative and qualitative) was posted in each class to allow for students to voluntarily participate in the study. Consent was implied if participants responded affirmatively. Using survey, end of course evaluations, and student emails, discussion threads and work sample data, the study investigated the use of an online synchronous tool (Elluminate) to determine if the tool was effective in (a) building community in online classes; (b) increasing student engagement with the content in online classes; and (c) increasing student interaction and collaboration with instructors and peers in online classes. In addition, the researchers assessed students' perception of Elluminate as a teaching and learning tool.

\section{Human Services}

After completing their SLU introduction to human services blended course, students were asked to complete a survey comprised of the 10 questions related to student perceptions of a sense of community and if this sense of community fostered a positive achievement of their learning outcomes. From a class of 5 students, 0 students elected to participate

Then after completing their SLU introduction to human services online course, students were asked to complete a survey comprised of the same 10 questions related to student perceptions of a sense of community and if this sense of community fostered a positive achievement of their learning outcomes. From a class of 25 students, five students elected to participate.

Both survey questionnaires included a 4-point Likert scale and ranking. Consent was implied if participants responded affirmatively.

\section{Social Work}

Likewise, instructors in the Graduate Social Work Department conducted two studies; one assessing the sense of community and another on students' perception of social presence in the online environment. For both studies, the instructor administered an anonymous online survey using Qualtrics software. The surveys used a measure of social presence developed by Chun-Wang et al. (2012). Social presence was described as a "second-order" construct" 
consisting of co-presence, intimacy, and immediacy, referred to as "first-order constructs." This was combined with two questions on satisfaction and learning taken from Garrison et. al. (2000) Community of Inquiry Framework. Original survey questions were on a 5-point Likert scale. Additionally, there were researcher created questions on demographics, such as gender, age, number of children, previous online experience, importance of student to student versus student to instructor connection, and a question on helpful strategies: What would you say are important strategies in the online environment that made you feel connected to (a) other students and to (b) the professor. As with the other studies conducted in education and human services, consent was implied if participants responded affirmatively.

In the study on social presence, the construct was compared in two formats. The first involved students in an introductory social work research methods class that is presented in a blended -asynchronous and synchronous learning environment, and allowed for interaction both independently and faceto-face. Students take this course in their first year of the program.

The second social work study involved one advanced social work research class, evidence-based social work practice, presented in an asynchronous learning environment. Students take this course in their second year of the twoyear graduate program. The asynchronous learning environment presents material through eCollege learning management system where each week's assignments are presented in weekly modules. Each module includes an audio lecture and assignments for that module, discussion questions, interactive exercises and assignments. In the blended format, the asynchronous environment is complemented by a weekly face-to-face meeting through the use of an online conferencing tool, Blackboard Collaborate (formerly Elluminate) where material is presented by the instructor via webcam. Like a traditional classroom, there is a whiteboard where the instructor and students are able to present necessary material; the ability to upload and present PowerPoint presentations; a microphone for oral delivery; and a chat area where written communication takes place as well.

The purpose of this study was to assess students' perception of social presence (SP) in the online learning environment, comparing students in the asynchronous course on Evidence Based Practice in Social Work, to students in the synchronous course in social work research methods. The study also assessed perceived social presence on students' satisfaction and sense of achievement.

A third study conducted in concert with the school of business, assessed graduate social work students' perceptions of a perceived sense of community in their graduate social work classes taught in a synchronous web based learning environment as compared to graduate masters of business administration students' perceived sense of community in their graduate business classes taught in an on-line asynchronous web based learning environment. The purpose of the study was to evaluate and compare the level of classroom community in two programs at Saint Leo University. The 
researcher was interested in the live web-based MSW program's ability to develop a sense of classroom community as compared to the strictly online setting in the MBA program.

\section{Methodology Conclusion}

In all studies instructors investigated student perception of building community and/or creating social presence in online classes. In one study the researcher investigated the difference in building community in online and face-to-face classes; in another study, the research compared community in live web-based and online formats across schools (Education and Social Services and Business). All studies utilized a Likert scale survey instrument. All surveys were administered anonymously with consent implied by responding to the survey. Surveys were administered in graduate and undergraduate classes. Instructors were located on the university's main campus and in center locations. Studies varied as to whether or not the survey also included openended and/or demographic questions

\section{Results}

\section{Education}

Students in Cohort A completed a voluntary exit survey with $25 \%$ participation rate. Survey results indicated that they felt community was built in the classroom when:

1. The professor responded to emails in a timely manner

2. They could access to course materials easily

3. The professor provided immediate feedback

4. The professor included extra resources to help with course assignments

5. They felt the professor cared about them and whether they learned the course material

Additionally, these students indicated they could have developed stronger community by holding the Elluminate session at a time that was more convenient to them. Students in Cohort B have not completed their exit survey. Overall, the preliminary results are promising and include:

1. Students are interested in doing well and view one another as resources for helping to meet their goals.

2. Explicit instructor modeling on the chatboard elicits similar behaviors of authentic questioning, supportive behaviors and sharing of ideas

3. When students miss an Elluminate session they email the instructor apologizing and explaining why. 
4. When students miss an Elluminate they view the recorded sessions.

5. After the session is over, students often stay in the session continuing their conversations with one another and the instructor.

6. Participating in scheduling of Elluminate/Collaborate sessions increased students' motivation to participate fully.

Student comments support the findings. For example, immediately following an Elluminate session a student wrote (email), “Thank you again for everything! The Tuesday night classes are so helpful! I really appreciate being able to discuss what we are learning."

In Graduate Education classes qualitative and quantitative data analysis revealed three themes. The implementation and utilization of Elluminate (a) decreased social isolation providing students opportunities to know and work with their peers; (b) increased students' interaction with the course content and their knowledge; and (c) increased communication and collaboration with peers and the instructor. Second, students responded the tool helped their (a) increased engagement with the course content; (b) understanding of the content, projects and assignments and professional insights; and (c) increased the value of their peers' insights and experiences. Third, open ended question responses identified Elluminate (a) provided direct, efficient and effective communication and access to the instructor; (b) increased value of and timeliness of instructor feedback; and (c) increased collaboration and connectedness with peers and the instructor.

Finally, students were asked to comment regarding their perceptions of the online conferencing tool. They responded they liked the ease of use; accessibility and availability of the instructor; and it "gave a personal and professional face to the class". Second, students responded the tool helped them gain greater understanding of the course content and increased their confidence in successfully completing online classes. Respondents also identified negatives associated with the tool. Primarily these clustered around two themes: (a) the time(s) the sessions were conducted and (b) students' lack of technology proficiency.

\section{Human Services}

Twenty-five online students were surveyed with five students responding to the survey. Five blended students were surveyed with zero responding to the survey. The researcher focused investigating on student perceptions of a sense of community and if this sense of community fostered a positive achievement of their learning outcomes. The survey posed 10 questions. Questions $1-9$ asked students to rank factors using the 4-point Likert scale (Table 1). The following factors were examined.

With regard to a sense of community and relationship to learning outcomes the quantitative data analysis revealed the following. The results 
revealed four fifths $(80 \%)$ of the respondents indicated the importance of the course instructor being part of the community and student technology experience being highly important in student perceptions of a sense of community. Almost two thirds $(60 \%)$ of the survey participants responded the importance of having interest in the course being highly important in student perceptions of a sense of community.

Table 1 Factor Ranking

\begin{tabular}{|c|c|c|c|c|}
\hline Factor & Not Important & $\begin{array}{c}\text { Slightly } \\
\text { Important }\end{array}$ & Important & $\begin{array}{l}\text { Highly } \\
\text { Important }\end{array}$ \\
\hline $\begin{array}{l}\text { Course instructor } \\
\text { being part of the } \\
\text { community }\end{array}$ & $0 \%$ & $0 \%$ & $20 \%$ & $80 \%$ \\
\hline $\begin{array}{l}\text { Student } \\
\text { technology } \\
\text { experience }\end{array}$ & $0 \%$ & $20 \%$ & $0 \%$ & $80 \%$ \\
\hline $\begin{array}{l}\text { Finding } \\
\text { similarities with } \\
\text { classmates }\end{array}$ & $0 \%$ & $0 \%$ & $100 \%$ & $0 \%$ \\
\hline $\begin{array}{l}\text { Sufficient time to } \\
\text { interact in } \\
\text { courseroom }\end{array}$ & $0 \%$ & $0 \%$ & $60 \%$ & $40 \%$ \\
\hline $\begin{array}{l}\text { Personal desire to } \\
\text { wanting } \\
\text { Community }\end{array}$ & $0 \%$ & $20 \%$ & $40 \%$ & $40 \%$ \\
\hline Interest in course & $0 \%$ & $20 \%$ & $20 \%$ & $60 \%$ \\
\hline $\begin{array}{l}\text { Positive } \\
\text { interaction with } \\
\text { other students }\end{array}$ & $0 \%$ & $20 \%$ & $20 \%$ & $40 \%$ \\
\hline $\begin{array}{l}\text { Have all course } \\
\text { materials by } \\
\text { first day of class }\end{array}$ & $20 \%$ & $40 \%$ & $20 \%$ & $20 \%$ \\
\hline $\begin{array}{l}\text { Increased } \\
\text { interaction \& } \\
\text { collaboration } \\
\text { with instructor } \\
\text { and classmates }\end{array}$ & $0 \%$ & $20 \%$ & $20 \%$ & $40 \%$ \\
\hline
\end{tabular}

Question 10 asked students to rank in order $(1-8)$ in importance $(1$ most important \& 8 least important) eight factors (Appendix A).With regard to a sense of community and relationship to learning outcomes the quantitative data analysis revealed the following. The results (Appendix B) revealed the top ranking reason (3) of the respondents is the student's interest in the course being highly important in student perceptions of a sense of community. The following two factors tied for second place ranking; course instructor being part of the community and technology experience.

\section{Social Work}

In the social presence study, 20 students participated (10 from each course). Preliminary quantitative survey results revealed in the hybrid course social presence was present with scores ranging from 1.4 to 2.4 ; with 
immediacy being the best experienced aspect of social presence, followed by coPresence. All students (100\%) reported satisfaction with the course and expressed they "learned much".

The fully online class was taught by several professors. Preliminary quantitative results revealed social presence scores ranged from 1.58 to 3.75 and $70 \%$ felt satisfied. Those who were not satisfied expressed needing samples of papers as examples of what's expected, more interaction, adding that emails and having personal telephone numbers were good. Instructional style may differ as well, which would be expected. Students in the hybrid class reported a greater sense of social presence, satisfaction, and learning, than those in the fully online class. Immediacy seems greater felt (so far) that copresence or intimacy. Immediacy in both courses seems greater felt (so far) than co-presence or intimacy.

In the second social work study, preliminary results evidenced those students in the synchronous web-based classes reported feeling a sense of community and a connection with both each other and their professor due to the nature of the delivery in the live web-based format.

Students stated that the weekly format that spans 16-weeks allowed them to accommodate work and family needs at the same time they completed their studies and the format did not diminish their level of connectedness with each other in the course room. They reported the professor organized the course room in both small and large group format in each class which then allowed students to interact with each other both visually and auditorily is if they were in the same course room.

Students who participated in strictly online courses with no live web-based video component expressed less satisfaction and less connectedness with the professor and with each other as compared to students who participated in the web-based video component. Further research results will be released at the completion of the study.

\section{Conclusion}

In all studies across all disciplines results (final and preliminary) revealed students reported a greater sense of community in online classes enhanced with emerging technologies including Elluminate and other synchronous web based technologies. In education, results disclosed introducing synchronous technologies increased engagement and motivation with the course content and increased the value and immediacy of instructor feedback. However, students identified students' participation could have increased is the synchronous online class times were scheduled that were more convenient to their schedules. Human services survey results corroborated those found in education; students' experiences with the infused technology were rated as highly important in creating a sense of community. Social work results supported those found in education and human services; students in the hybrid 
class reported a greater social presence, satisfaction and learning than those enrolled in the fully online class that did not infuse synchronous technologies.

\section{References}

Allen, I., \& Seaman, J. (2011). Going the distance: Online education in the United States, 2011. Babson Survey Research Group and Quahog Research Group, LLC. Retrieved from http://www.onlinelearningsurvey.com/reports/goingthedistance. pdf

Arbaugh, J.B. (2008, June). Does the community of inquiry framework predict outcomes in online MBA courses? The International Review of Research in Open and Distance Learning. Retrieved from http://www.irrodl.org/index.php/ irrodl/article/view/490/1045

Arbaugh, B., Bangert, A, \& Cleveland-Innes, M. (2010) Subject matter effects and the community of inquiry framework. The Internet and Higher Education, 13(1-2).

Bikowski, D. (2007, Summer). Internet relationships: Building learning communities through friendship, 6, (2). Retrieved www.ncolr.org./jiol

Dennen, V. P., Darabi, A. A., \& Smith, L. J. (2007). Instructor-learner interaction in online courses: The relative perceived importance of particular instructor actions on performance and satisfaction. Distance Education, 28(1), 65-79.

Drouin, M. A. (2008). The relationship between students' perceived sense of community and satisfaction, achievement, and retention in an online course. Quarterly Review of Distance Education, 9(3), 267-284.

Garrison, D. R. (2007). Online community of inquiry review: Social, cognitive, and teaching presence issues. Journal of Asynchronous Learning Networks, 11(1), 6172.

Garrison, D.R., Anderson, T., \& Archer, W. (2000). Critical inquiry in a text-based environment: Computer conferencing in higher education. The Internet and Higher Education, 2 (2-3); 1-19.

Kupczynski, L., Ice, P., Wiesenmayer, R., \& McCluskey, F. (2010). Student perceptions of the relationship between indicators of teaching presence and success in online courses. Journal of Interactive Online Learning, 9(1).

Lehman, R. \& Conceicao, S. (2011). Creating a sense of presence in online teaching. San Fransisco, CA: Jossey Bass.

Liu, X., Magjuka, R. J., Bonk, C. J., \& Lee, S. (2007). Does sense of community matter?: An examination of participants' perceptions of building learning communities in online courses. Quarterly Review of Distance Education, 8(1), 924.

O’Bannon, B. \& Britt, V. (2012). Creating/developing/using a wiki study guide: Effects on student achievement. Journal of research on technology in education, 44(4), 293-312.

Ouzts, K. (2006). Sense of community in online courses. Quarterly Review of Distance Education, 7(3), 285-296.

Palloff, R. \& Pratt, K. (2003). The virtual student. A profile and guide to working with online learners. San Francisco: Jossey Bass.

Rheingold, H. (2010). The virtual community: Homesteading on the electronic frontier. Cambridge, MA: The MIT Press. 
Smith, S. D., \& Caruso, J. B. (2010). The ECAR study of undergraduate students and information technology, 2010 (Research Study, Vol. 6). Retrieved from Educause, Center for Applied Research website: http://www.educause.edu/

Vesely, P., Bloom, L., \& Sherlock, J. (2007, September). Key elements of building online community: Comparing faculty and student perceptions. Journal of Online Learning and Teaching, 3 (3), 1-12.

Yuen, S., Yaoyuneyong, G., \& Yuen, P. (2011). Perceptions, interest, and use: Teachers and Web 2.0 tools in education. International Journal of Technology in Teaching and Learning, 7(2), 109-123.

Young, S. \& Bruce, M. (2011). Classroom community and student engagement in online courses. Journal of Online Learning and Teaching, 7(2). Retrieved from http://jolt.merlot.org/vol7no2/young_0611.htm

Appendix A. Factors

\begin{tabular}{|c|c|c|c|c|c|c|c|c|}
\hline Factor & 1 & 2 & 3 & 4 & 5 & 6 & 7 & 8 \\
\hline $\begin{array}{c}\text { Course instructor being } \\
\text { part of the community }\end{array}$ & 1 & 2 & & 1 & & 1 & & \\
\hline Technology experience & 1 & & & 1 & & & 1 & 2 \\
\hline $\begin{array}{c}\text { Finding similarities with } \\
\text { classmates }\end{array}$ & 1 & 1 & 1 & & 1 & 1 & 1 \\
\hline $\begin{array}{c}\text { Sufficient time to } \\
\text { interact in courseroom }\end{array}$ & 1 & 1 & & 2 & & 1 & 1 \\
\hline $\begin{array}{c}\text { Personal desire to } \\
\text { wanting community }\end{array}$ & 1 & & 1 & & 1 & & 1 & \\
\hline $\begin{array}{c}\text { Interest in course } \\
\text { Positive interaction with } \\
\text { other students }\end{array}$ & 3 & & 1 & & 1 & & 2 \\
\hline $\begin{array}{c}\text { Have all course } \\
\text { materials by first day of } \\
\text { class }\end{array}$ & & 1 & & & & & 1 \\
\hline
\end{tabular}

Appendix B. Values Ranking

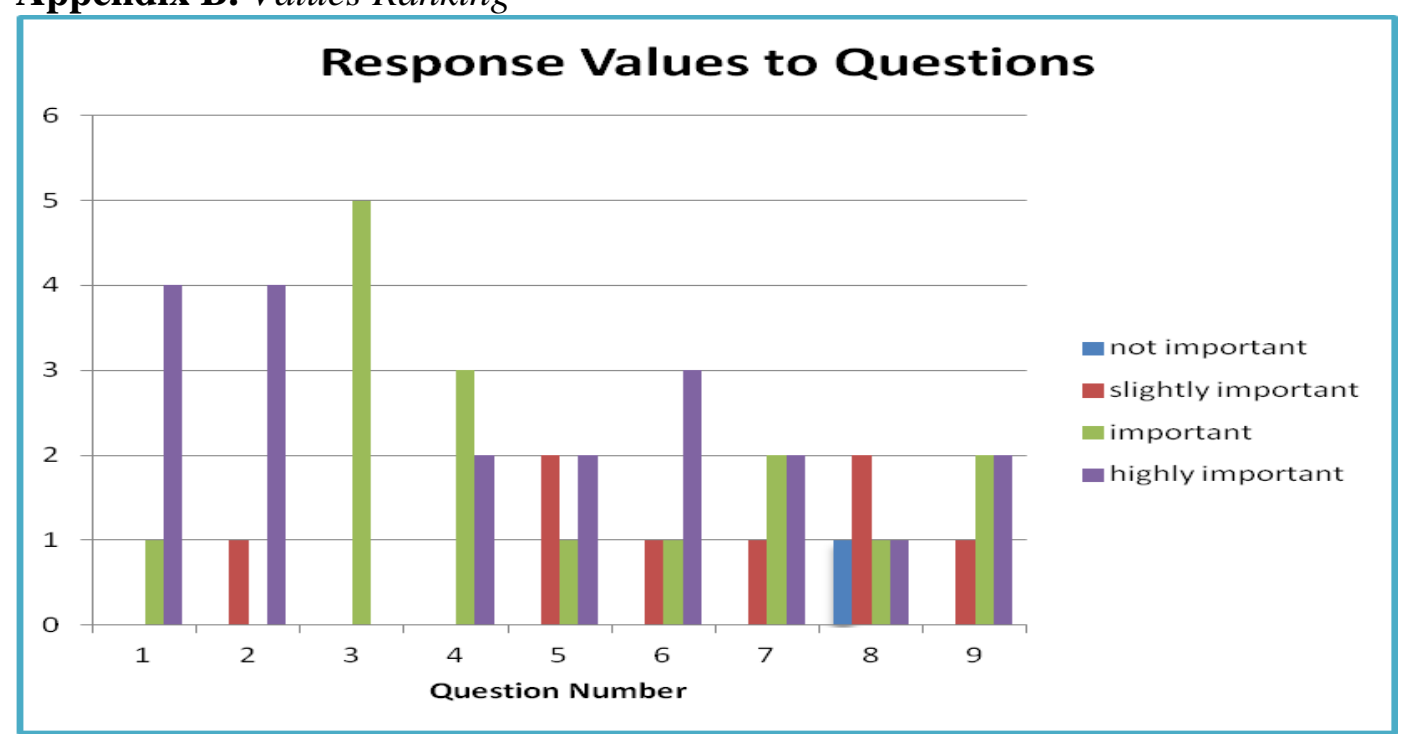


